\title{
Sexism in Haya Language Personal Names Selection
}

\author{
Adventina Buberwa ${ }^{1}$ \\ University of Dar es Salaam
}

\begin{abstract}
This paper examines sexism in naming focussing on the meaning of Haya personal names used in Haya community of North Western Tanzania. It is based on the assumption that some conscious personal names are selected in favour of men. This disparity is well examined by using the Critical Discourse Analysis approach. The paper presents field data from Bukoba Rural district in Kagera Region. The results reveal that meanings of male names were associated with high worthwhile the meanings of female names were associated with low worth. This was justified by the point that Haya male names referred to male as a saviour and helper of the family and society, a strong person, a fighter, a winner, rich and famous person while female names were connected with love, attraction, comfort, soothes and parents disappointment for having a baby girl. The study found that names of female children indicate an important argument that parents consider female child as a burden and liability. Generally, it was observed that selection of some Haya personal names was done in discriminatory manner that need an urgent emphasis on the value of names of girls in families and society in general.
\end{abstract}

Key words: sexism, personal names, Haya language, name selection

\section{Introduction}

In ordinary speech, the terms sex and gender are often used interchangeably. However, the terms are different. The difference between these terms is that sex refers to a person's biological characteristics (sex) while gender refers to social roles based on the sex of a person. Gender is not the causal result of sex but a set of relations and not an individual's attribute (Butler, 1999). On the other hand, sexism refers to discrimination based on individual's sex (Lei, 2006). Basically in this paper, sexism means the situation where by one sex is superior to another. According to Larsen (2006), sexism in language exists when the language devalues members of a certain sex. In this case, this paper contributes to sociolinguistics by considering the phenomenon that meaning of some names from Haya language maintains sexism whereas male names identify men as standard and strong group while female names relegate women to be inferior group. Collection of data for this paper was based on qualitative techniques. This involved collection of field data which was conducted in July to August, 2018 in Bukoba Rural District in Kagera region where by a total of 60 people aged 45-65 from Ruhunga Ward were consulted. Structured interviews and focused group discussions of six (6) parents were done to explore the factors behind male and female names selection. A total of 30 respondents were interviewed and 30

${ }^{1}$ Adventina Beberwa is a lecturer of Sociolingusitics in the Department of Kiswahili Language and Linguistics, Univesversity of Dar es Salaam, Tanzania. Email: buberwa@udsm.ac.tz 
respondents were consulted through focused group discussion. Interviews and discussions were recorded in a tape recorder. The sample used in this study was as presented in Table 1 below:

Table 1

Sample of the Study

\begin{tabular}{|l|l|l|l|}
\hline Research Methods Used & Male & Female & Total \\
\hline Interview & 15 & 15 & 30 \\
\hline Focused Group Discussion & 15 & 15 & 30 \\
\hline Total & $\mathbf{3 0}$ & $\mathbf{3 0}$ & $\mathbf{6 0}$ \\
\hline
\end{tabular}

Generally, the data was analysed by focussing on the meanings of Haya male and female names with the aim of exploring various sexism elements connected with those names.

\section{Haya Language Setting}

Haya language is a Bantu language spoken by Haya people in Kagera region Tanzania mainland. The language was linguistically classified as Haya - Jita Group by Maho (2009) and it falls under the JE22. It has eight dialects which are Hamba, Ihangiro, Nyakisaka, Yoza, Endangabo, Bumbire and Mwani (Muzale, 2005). Buberwa (2010) reports that the coming of the agents of colonialism especially missionaries and traders affected the medium of interaction among the Haya people whereas before the coming of these agents, Haya community used Haya language in all aspects. The use of English and other foreign languages in formal education, administration and in other social issues is one of the effects of colonialism in Haya community.

The effect of colonialism is also reflected in naming practices where by many first names of the Haya people are of foreign origin. On the other hand, names like Mukabangereza which means 'a wife of the British' reflect the presence of British people in the land of Haya people. Generally, the language especially names are connected with different social, economic and political activities of a given community.

\section{General Review of Studies on Personal Names}

There is a considerable number of scholars who have conducted studies on personal names based on morphological and sociolinguistic perspectives. Scholars (Baitani, 2010; Majie-Okyere, 2015; Mphande, 2006; Rubanza, 2000) conducted studies on morphology of personal names. It was observed that personal names may indicate various linguistic structures including phonological and morphological processes and meaning. Studies conclude that personal names can be divided into three categories which are derived names, underived names and compound names. Contrary to these studies, the current paper investigates how the selection of some Haya personal names indicates discrimination of one sex over the other: that is sexism.

On the other hand, Agyekum (2000; Buberwa, 2017; Hargreaves, Colman \& Sluckin, 1983; Seeman, 1983) conducted research on personal names by investigating some sociolinguistic issues informing names. The results reveal that personal names are associated with social issues 
in which the baby is born. These include social, political and economic environment. Seeman (1983) points out that in some languages, names are also selected consciously whereby boys' names prescribe prosperity while girls' names prescribe attractiveness. Since the main objective of the study was to analyse unconscious names, conscious personal names were not well analysed. This paper focuses on the issue by analysing conscious personal names from Haya language spoken in North-western Tanzania.

Carpusor and Loges (2006) have done research about the effect of name based ethnic stereotypes on housing discrimination in Los Angeles. The aim of the study was to test if there is discrimination in housing against a person's ethnicity in Los Angeles County. It was observed that names play a role in landlord's decisions to encourage prospective tenant. Arab sounding names were likely discouraged from visiting apartments for rent than a person with a White sounding name. Also, people with African American sounding names were likely to be discouraged than an applicant with a White sounding name. However, the African American sounding names applicants were treated significantly worse than the Arab sounding applicants. In relation with the current paper, the study reveals that personal names may disclose social position, ethnic background and tribal affiliations. This was also noted by Daniel and Daniel (1998). However, the current paper focuses on discrimination in personal names selection in Haya language of Northwestern Tanzania.

\section{General Review of Studies on Sexism}

The central concern of this paper is to examine sexism in selection of Haya personal names. Therefore, reviewing literature about sexism is something unavoidable. Even though complaints on discrimination and subordination in Africa and outside Africa exist, there has been very little written on discrimination through sexist language especially on how sexism is reflected in naming practices.

However, some scholars have conducted studies on sexism focussing on fields like education, economics, language, hip hop culture, philosophy and onomastic. With regards to the relationship between sexism and inequality, Jayachandran (2015) has conducted research on gender inequality in developing countries. The paper argues that sexism relationship can be explained by development processes and society specific factors. The paper concentrates on how cultural norms cause gender gap whereas males are favoured in education, health and personal autonomy in Africa in general. The current paper takes departure from the study by investigating how sexism is revealed from the meanings of selected Haya personal names.

The study by Pelak (2008) examines sexist naming of women's athletic teams at four-year colleges and universities in the southern United States. It focuses on the extent to which sexist names are used, the characteristics of schools that use sexist names, and relationship between naming and distribution of athletic opportunities among female and male students. The study noted that there is usage of some sexist names for women in basketball teams and female students' athlete teams. It was argued that sexist naming may contribute to gender equity of an athletics department which later determines the level of opportunities for women students. 
In the issue under review, Ukhun (2003) examines sexism against women in rural Esan in Edo state in the Southern Nigeria. It was observed that sexism in Africa is a metaphysical issue that results from a spiritual bond between African women and God or gods. The point was cemented by the fact that African girl may be forced to accept a man as husband against her will, since it is believed that if she refuses the spirit of the land can punish her. In relation with this study, the current paper has also noted that there are some supernatural issues involved in selecting Haya personal names. However, the current paper deals with sexism in naming focussing on meanings of entire names.

Fromkin and Rodman (1993) analysed the role of language in reinforcing speech habits and events that reflect sexism. The study argues that there are words for women with abusive and sexual implications which are used consciously or unconsciously. It was concluded that the language itself is not sexist but the use reflect sexism. From this point of view, the current researcher is interested on examining how sexism is reflected in the meanings of Haya personal names.

In an analysis of sexism in language, Lei (2006) discusses sexism in English language from two aspects which are sexism in words and sexism in proverbs. Common sexism words in English were mentioned including "man", "he", "him" and "his". Sexism is also identified in the distinction between "Mr" and "Miss", which is not parallel with a pair of male tittles showing if a person is married or not. In the side of sexism in proverbs, Lei (2006) presents some proverbs that reflect sexism. See the following examples:

i. He who follows his wife's advice; will never see the face of God.

ii. A woman is like a lemon; you squeeze her and throw her away.

iii. Seven women in their right senses are surpassed by a mad man (Lei, 2006, p. 90).

Larsen (2006) has done a study on sexism in relation to visual imagery which is presented in hip hop culture. The study tries to find out the discriminatory elements found in hip hop. It was observed that it is obvious to see videos presenting women in bikinis or topless together with fully clothed men. While women are dancing shaking their buttocks, men throw money at women's buttocks. This kind of behaviour is referred as sexism, where women are presented as prostitutes who can do anything for money. While the study concentrates on sexism in hip hop culture, the current paper focuses on how Haya male and female are treated in name selection practices with regards of sexism.

Moreover, Shijith and Sekher (2017) examine the discrimination against girl child in India. They focus on naming practices of girl children in Satara district of Maharashtra. Factors behind the girl child discrimination of naming her 'Nakusa' which means 'unwanted were well examined. It was observed that the situation is an outcome of parents' attitude towards daughters whereas they give 'Nakusa' names to their children since they hope that the next child will be a boy. Girls are unwanted due to the assumption that daughters are associated with loss or double loss. It is believed that expenses of upbringing the girl child are lost when she is married. This kind of superstition was also noticed in the current paper as it will be seen in the data analysis section. 
Obasola (2013) presents analysis of issues concerning African culture in relation with gender discrimination especially on girl child education. The paper points out that a girl child in African culture is seen as bad luck. She is not given education and in some cases education given to her is just to make her useful in her husband's house. It is recommended that the society has to empower women and give them adequate and equal attention. Apart from this paper, the current paper deals with sexism in Haya personal names selection where socio-cultural issues informing those names are well presented and discussed.

The study by Murugi (2003) discusses about sexist language use in Nairobi Kenya. The study examines sexist language used by male University students and touts by using English, Kiswahili and Sheng languages. It deals with how these languages promote abuse against women especially female students and passengers basing on the assumption that women are socially oppressed, derogated and subordinated through the use of sexist language. In the context of the study, it was reported that there is a notable number of men in Nairobi Kenya who use language to marginalise, abuse and demean women. The study reveals that women are seen to be productive objects and that they are good for their reproductive organs or ability to sex. In relation to that, sexist language used by male University students and touts reflect female discriminated culture in the institution whereby female are regarded as second to male and consequently as sex objects. It was concluded that language plays a major role in creating, transmitting and sustaining gender differences in sociecy.

Cheng and Ghajarieh (2009) have done a study on issues concerning sexist language in classroom where gender bias in education setting was well analysed. The study analyses the issue in areas of teacher-talk to students, students to students and in textbooks in Malaysia. In this study, high school textbooks were collected from the education library. The textbooks analysed revealed that there is existence of sexist attitudes. Also, the textbooks had unfair picture of gender. It was observed that there are various sexist discourses that show unequal rights for male and female students. The study focuses on sexism in classroom situation while the current paper focuses on sexism in naming practices.

\section{The Theoretical Approach}

This paper is based on the Critical Discourse Analysis approach developed by Dijk (2001). It is an interdisciplinary approach used in the analysis of discourse focusing on power and its relationship. Its basic assumption is that language should be examined as a form of cultural and social practice. Thus, it should be analysed by describing the social context involved. It holds that there is a relationship between language and power whereas dominance, social power and inequality can be reflected in the discourse. The approach emphasises on the relationship between language, society and inequality. However, there is critique that the approach deals with social research and it is not linguistic enough. It should be noted that the Critical Discourse Analysis approach aims at various aspects of societal disparities and inequalities. Using this approach, the researcher have analysed Haya personal names within the context of the Haya community. Also, the approach was used in examining sexist elements found in Haya naming practises. The results concur with the assumption that power, dominance and inequality can be 
reproduced by the discourse. The names analysed revealed that male children in Haya community are glorified and favoured. They are promoted as superior and heroes. On the other hand, female names reflect the fact that female children are born to be married tools for attraction and sex. In this regard, the approach was viewed as ideal for this paper.

\section{Sexism and Meanings of Haya Personal Names}

Haya personal names meanings are not an up hazard phenomenon but culturally meaningful as an indicator of real life experiences of people (Baitani, 2010, p. 62). However, it should be noted that like any African community, Haya community experience disparity on the basis of sex; for instance, sexism. This section tries to present how this disparity is reflected in Haya personal names meanings. The section is divided into two subtopics which involve the analysis of meanings of male and female names. The following subtopic is about meanings of Haya male names.

\section{Meanings of Haya Male Names}

Analysis of the meanings of Haya male names cannot be separated with Haya culture and traditions. Haya community belongs to patrilineal traditions where by sons are more important and more valuable than daughters. It was reported through interviews that male children are more preferred in aspects of rituals, inheritance and education. The names of male children collected can be grouped into three categories based on their meanings. The categories include names referring a male child as a family's and society's helper and saviour, names referring a male child as a strong and fighter person, and names referring a male child as a winner, rich and famous person. These categories are well presented in the following sections.

Names Referring a Male Child as a Saviour or Helper of the Family or a Society Of the total male names collected, it was observed that some Haya male names refer to male child as a saviour or helper of a given family or the whole society. The following examples represent names of this category:

Table 2

Names Referring to a Male Child as a Saviour or Helper of the Family and Society

\begin{tabular}{|r|l|l|}
\hline \multicolumn{1}{|l|}{ Na. } & Personal Names & Meaning \\
\hline 1. & Mulokozi & Saviour \\
\hline 2. & Mujuni & Helper \\
\hline 3. & Kajuna & He helps \\
\hline 4. & Mwombeki & The builder \\
\hline 5. & Kaijage & Has come with fortune \\
\hline 6. & Mugisha & Blessing \\
\hline
\end{tabular}

The names listed in Table 2 above denote the role of male children and parents expectations over the son. During interviews, parents explained about the factors behind male names selection. It was reported that the child was named Mulokozi because parents believe that a male child is the 
saviour of the family since the female child leaves the family after her marriage. Also, it was reported that names Mwombeki, Kaijage and Mugisha reflect the beliefs and expectations of parents and relatives that getting a male child is fortune and blessing from God. Conclusively, this category of male names reflects how sons in Haya community are more preferred than daughters.

Names Referring to a Male Child as a Strong and Fighter Person

Another category of Haya male names explored was the names that refer a male child as a strong and fighter. We came across the following male names under this category:

Table 3

Names Referring to a Male Child as a Strong and Fighter Person

\begin{tabular}{|l|l|l|}
\hline Na. & Personal Names & Meaning \\
\hline 1. & Murashani & Fighter \\
\hline 2. & Mbogo & Buffalo \\
\hline 3. & Nkuba & Thunder \\
\hline 4. & Rutinwa & He who is feared \\
\hline 5. & Kabigumila & He who survives in hardship \\
\hline
\end{tabular}

As the data in Table 3 reveals, male names reflect the social fact that a son in Haya community has a greater status whereas the family and the society consider him as someone who is strong like buffalo or thunder. Also, a son is perceived as someone to be feared and he can survive in time of hardship. The names above denote Haya parents' thoughts about their sons. It was reported in all focused group discussions that sons are better than daughters in terms of decision making and problem solving. This kind of assumption convinces the researcher to conclude that selection of some Haya male names is done in discriminatory manner.

\section{Names Referring to a Male Child as a Winner, Rich and Famous Person}

Some Haya male names collected reflect a male child as a winner, rich and famous person. Examples numbered 1 to 6 in the Table below represent the names of this category:

Table 4

Names Referring to a Male Child as a Winner, Rich and Famous Person

\begin{tabular}{|c|l|l|}
\hline \multicolumn{1}{|l|}{ Na. } & Personal Names & Meaning \\
\hline 1. & Rugarabamu & He who succeeds \\
\hline 2. & Rumanyika & He is famous \\
\hline 3. & Rwechungura & He who never despairs \\
\hline 4. & Mutungi & He who is rich \\
\hline 5. & Rugaimukamu & He who escapes from problems \\
\hline 6. & Rutasingwa & He who is never defeated \\
\hline
\end{tabular}

The names in Table 4 above promote male child superiority. Respondents who were consulted through interviews reported that the names were selected for male children because parents had positive expectations for their male children. They expect their male child to be rich, winners and to succeed in everything they do. From this point of view, it was observed that parents are ready 
to invest more in sons than daughters expecting their son to be rich, famous and succeed in life. In that case, sons are favoured than daughters. These results comply with the argument made by Threadgold (1988, p. 172) that language expresses race and gender ideologies glorifying men as heroes. The meanings of Haya names of male children presented under this section show that male children are superior and heroes.

\section{Meanings of Haya Female Names}

Under this section, four categories of Haya female names have been discussed. These include names associated with love and attraction, names associated with a male child as a wife, names associated with comfort and soothes and names associated with parents' disappointment.

Names Associated with Love and Attraction

Contrary to Haya male names discussed in the previous category, Haya female names under this category refer to love and attractiveness of female child. See the following examples in Table 5 below:

Table 5

Names Associated with Love and Attraction

\begin{tabular}{|r|l|l|}
\hline Na. & Personal Names & Meaning \\
\hline 1. & Kokugonza & The one to be loved \\
\hline 2. & Kokuleeba & The one to look at \\
\hline 3. & Kokunura & The one who is sweet \\
\hline 4. & Kokwenda & The one to be loved \\
\hline 5. & Karungi & The one who is beautiful \\
\hline 6. & Kokutona & The one to decorate \\
\hline
\end{tabular}

The meanings of names in Table 5 trigger the assumption that female child is born to be loved and to attract people. It was reported by respondents of both interviews and focussed group discussions that the names above were given to female children because basically in Haya culture and traditions women have roles of bringing up children, looking after the house and to cater to their husband's needs. This point makes the researcher to be convinced that meanings of some Haya female names denote the treatment of daughters as a minor group. The meanings of these names in relation to male names discussed the previous category entail that female children are regarded as inferior to men and are not expected to aspire as high as males.

Names Associated with a Female Child as a Wife Another category of Haya female names involves names that refer a female child as a wife. See the following examples:

Table 6

Names Associated with a Female Child as a Wife

\begin{tabular}{|r|l|l|}
\hline Na. & Personal Names & Meaning \\
\hline 1. & Mukatabazi & Wife of the attack \\
\hline
\end{tabular}




\begin{tabular}{|r|l|l|}
\hline 2. & Mukaliitira & Hitler's wife \\
\hline 3. & Mukagendage & A wife of the one who is doing well \\
\hline 4. & Mukabangereza & Wife of the British \\
\hline 5. & Mukabakama & A wife of kings \\
\hline
\end{tabular}

Surprisingly, the names under discussion refer to a female child as a wife of someone even though no one knows if an individual is interested in being married. This kind of social standing brought a hot discussion during interview and focused group discussion. Some respondents emphasised that female child is born to be married not otherwise. On other hand, it was reported that those names were used in old times when many female children were not going to school. Their only role was to be married and to fulfil her husband's needs. The point was cemented by the supernatural beliefs that a woman was created by God for a man.

In relation to male child names discussed previously, female names denote the fact that daughters experience less expectations and worth from their parents. This was supported by respondents' argument that it is better to invest in males children because doing so for female child is to invest for another family's advantage. This kind of superstitions was also observed by Croll (2000) in his study about endangered daughters in Asia. He concludes that marriage is the most cultural factor for parents' strong preference for sons. Generally, the names under this category prove the presence of sexism in some Haya personal names. The current paper suggests that these names should be avoided in order to allow female children to think of moving into various professions instead of placing themselves as wives and have only the role of fulfilling their husbands' needs.

Names Associated with Comfort and Soothes

The data collected reveal that some Haya female names refer to a female child as someone who provides comfort and soothes. The following are examples of those names:

Table 7

Names Associated with Comfort and Soothes

\begin{tabular}{|l|l|l|}
\hline Na. & Personal Names & Meaning \\
\hline 1. & Kokumaramara & The one who consoles \\
\hline 2. & Kokuhumuliza & The one who consoles or soothes \\
\hline 3. & Kokushekya & The one who makes people laugh \\
\hline
\end{tabular}

As per examples mentioned above, some Haya female names denote the female child as a person who makes life pleasant by providing little luxury contrary to male child who is expected to be strong, tough, brave, winner and aggressive. This kind of disparity on the basis of sex shows that the selection of some Haya personal names does not follow equal gender status between females and males. It should be noted that there are some females who have moved into different professions including the ones which were regarded as male jobs. Therefore, it is better to select female names that show courage and more worth expectations rather than addressing them as tools of entertainment. 
Names Associated with Parent's Disappointment

Some Haya female names describe parents' disappointment on getting a female child. See the examples in Table 8 below:

Table 8

Names Associated with Parent's Disappointment

\begin{tabular}{|l|l|l|}
\hline Na. & Personal Names & Meaning \\
\hline 1. & Nshekibweki & What can make me laugh \\
\hline 2. & Nshubemuki & What can I repeat \\
\hline 3. & Wokueleza & The one to give to... \\
\hline 4. & Fakulera & Just raise her (raising) \\
\hline
\end{tabular}

The names in Table 8 above reflect the fact that some parents in Haya community prefer male children than female children. Therefore, they celebrate when a male child is born but the birth of a female child is often viewed as a crisis. The situation was also observed in Satara district of Maharashtra, India by Clark (2000) in his paper entitled 'Son Preference and Sex Composition of Children: Evidence from India'. The data for the current paper shows that parents selected the names Nshekibweki and Nshubemuki for their female children because they were disappointed to get female children. Therefore, they were not happy and they did not want to repeat since they could get another female child. On the other hand, names Kokuhabwa and Kuhabwa describe the perception of parents that the female child was given by God out of parents' will. It was also reported that the name Fakulera was selected for the female child because parents had a perception that raising female children is wasting of resources. These examples show discrimination through name selection in Haya community. The names above identify parents' thoughts about the birth of their female children. The names presented under this category reinforce the assumption that having female child is liability while having a male child is necessity.

\section{Conclusion}

The main objective of this paper was to examine how sexism elements are reflected in Haya personal names meanings. The study found that sexism in personal names selection is connected with culture and traditions of a given society. The names examined show that the intension of naming children was more than identity. Names analysed describe sexism and son preference which are influenced by culture, traditions and beliefs. It was observed that there is unfair difference in the way male and female children's names are selected. The paper recommends avoiding names that encourage sexism in order to build a united and happy society.

\section{References}

Agyekum, K. (2006). The socio-linguistic of Akan personal names. Nordic Journal of African Studies 15(2), $206-235$.

Baitani, (2010). A morphosemantic analysis of Ruhaya personal names, (MA Thesis). University of Dar es Salaam.

Buberwa, A. (2017). Kiswahili personal names selection in Tanzania: A sociolinguistic analysis. Kiswahili, 80(1), 38 - 57. 
Buberwa, A. (2010). Investigating sociolinguistic aspects of place names in Ruhaya in Northwestern Tanzania. Unpublished M.A Dissertation, University of Dar es Salaam.

Butler, J. (1999). Gender trouble. New York: Routledge.

Carpusor, A. G., \& W. E. Loges (2006). Rental discrimination and ethnicity in name. Journal of Applied Social Psychology 36 (4): 934 - 952.

Cheng, K. K. Y., \& Ghajarieh, A. B. B. (2009). Gendered language in classroom. Journal of Asia TEFL, 6(3) $27-43$.

Clark, S. (2000). Son preference and sex composition of children: Evidence from India. Demography, 37(1), $95-108$.

Croll, E. J. (2000). Endangered daughters: Discrimination and development in Asia. New York: Routledge.

Daniel, E., \& Daniel, L. (1998). Preschool children selection of race related personal names. Journal of Black Studies, 28, 471-491.

Fromkin, V., \&. Rodman, R. (1993). Introduction to language. London: Holt, Rinehart and Winston.

Hargreaves, D. J., Colman, A., \& Sluckin, W. (1983). The attractive names. Journal of Human Relations, 36, 393-402.

Jayachandran, S. (2015). The roots of gender inequality in developing countries. The Annual Review of Economics 7, 63-88.

Larsen, J. K. (2006). Sexism and misogyny in American hip- hop culture. Unpublished MA Thesis, University of Oslo.

Lei, X. (2006). Sexism in language. Journal of Language and Linguistics, 5(1), 1-8.

Obasola, K. E. (2013). Gender Discrimination and Cultural Anachronisms in African Societies: Implication for girl child education. International Journal of Social Science and Education, 3(4), 1027-1034.

Marjie-Okyere, S. (2015). A linguistic survey of types of names among the Babukusu of Kenya. Global Journal of Human Social Science, 15(3), 56-68.

Mphande, L. (2006). Naming and linguistic Africanism in African American culture. In J. Mugane (Mh.) Selected proceedings of the 35th annual conference on African linguistics (pp. 10113).

Murugi, K. L. (2003). Language as a tool of abuse against women: The case of the language of Matatu Touts and University Students in Nairobi. Unpublished M.A Thesis, University of Nairobi.

Muzale, H. R. T. (2005). Complex Issues in lexical data collection: Cases from Ruhaya. Occasional Papers in Linguistics, 1, 155-166.

Obeng, G. (1998). Akan death-prevention names: A pragmatic and structural analysis. Names, 46(3), 163-187.

Pelak, C. F. (2008). The relationship between sexist naming practices and athletic opportunities at colleges and universities in southern United States. Sociology of Eduacation, 81(2), 89210.

Rubanza Y. I. (2000). The linguistic creativity of haya personal names. Kiswahili Journal, 63, 1122.

Seeman, M. V. (1983). The unconscious meaning of personal names. Names: Journal of Onomastics 31(4), 237-244. 
Shijith, V. P., \& Sekhe, T. V. (2017). 'Unwanted' is my name: Bias surrounding the Nakusa Girls of Maharashtra. Sociological Bulletin, 66(1), 58-74.

Threagold, T. (1988). Stories of race and gender. In D. Berch, \& O. Toole (Eds.), Functions of style. London: Printers Publishers.

Ukhun, C. E. (2003). The metaphysical sexism and an African studies. Ufahamu: A Journal of African Studies, 30(1), 62-82. 